\title{
PARTICLE LADEN FLOW INVESTIGATIONS IN SPECIAL PURPOSE DRY-ICE BLASTING APPLICATIONS
}

\author{
ARTHUR RUDEK ${ }^{1,2}$, GERALD RUSS ${ }^{1} \&$ BARRY DUIGNAN ${ }^{2}$ \\ ${ }^{1}$ Hochschule Darmstadt, University of Applied Sciences, Germany. \\ ${ }^{2}$ Dublin Institute of Technology, Ireland.
}

\begin{abstract}
A high speed camera investigation is presented into the behavior of $\mathrm{CO}_{2}$ dry-ice particles in an application of dry-ice blasting to the defouling of commercial aircraft engine compressors. An image acquisition system is deployed in the compressor section of an aircraft engine and is used to determine the evolution of dry-ice particle size and velocity from the nozzle exit to the entrance to the engine's high pressure compressor as the engine is cranked. A comparison study between $\mathrm{CO}_{2}$ dry-ice particle laden flows and airflows with single Polyoxymethylene (POM) particles of various diameters is also presented. Measurements are made using a range of blasting system pressures and using sonic and supersonic blasting nozzles. The behavior of large $\mathrm{CO}_{2}$ dry-ice particles $\left(d_{P} \geq 1 \mathrm{~mm}\right)$ in this discontinuously and inhomogenously laden flow is compared to that of single POM particles under similar flow conditions and is found to behave similarly. The experiments presented turn out to be useful for supporting development of special purpose dry-ice blasting systems.
\end{abstract}

Keywords: aircraft engine defouling, $\mathrm{CO}_{2}$ dry-ice blasting, $\mathrm{HSC}$ experiment, solid particle laden flow.

\section{INTRODUCTION}

The work presented here arises from ongoing research being carried out in cooperation with Lufthansa Technik AG into the use of $\mathrm{CO}_{2}$ dry-ice blasting for the defouling of aircraft engine compressors. In this technique, dry-ice particles are shot from a nozzle into the fan inlet of the engine as it is being cranked using the starter motor. A general description of such systems is given by Giljohann et al. [1]. For the development of a deeper understanding of this process, a detailed investigation of the flow patterns and the effect on particle parameters is required. The most important of these are the distribution of particle size and velocity as they progress through the engine, and the effect of system parameters such as system pressure, nozzle type and engine cranking speed. A general description of compressed air driven $\mathrm{CO}_{2}$ dry-ice blasting systems can be found in Foster [2] and Stratford [3]. Although this work is focused on aircraft engine cleaning, its outcomes are of general interest for direct $\mathrm{CO}_{2}$ dry-ice cleaning applications.

Outcomes from high speed camera (HSC) experiments on conventional convergent-divergent dry-ice blasting nozzles are discussed in Spur et al. [4], Haberland [5] and Redeker et al. $[6,7]$. The main findings from these works are compared in Table 1. A significant difference in minimum particle diameter can be seen between Spur et al. [4] and the results of Haberland [5] and Redeker et al. [6, 7]. A difference in velocity ranges can be seen in the outcomes from Spur et al. [4] and Haberland [5] compared to Redeker et al. [6, 7] where the maximum particle velocities encountered are significantly higher.

Krieg [8] uses the findings from Spur et al. [4] to predict $\mathrm{CO}_{2}$ particle emerging velocity for basic studies of the cleaning mechanisms, although he states particle diameters and velocities being strongly dependent on system parameters. One significant problem of $\mathrm{CO}_{2}$ dry-ice blasting is the necessity of utilizing compressed air, which leads to a low 
Table 1: Comparison of experimental outcomes from literature.

\begin{tabular}{lllll}
\hline Range & Spur et al. [4] & Haberland [5] & Redeker [6] & Redeker et al. [7] \\
\hline Pressure & $3 \ldots 12$ bar & $6 \ldots .20 \mathrm{bar}$ & 12 bar & $6 \ldots 14$ bar \\
Diameter & $1.0 \ldots 3.0 \mathrm{~mm}$ & $0.4 \ldots 1.0 \mathrm{~mm}$ & ca. $0.1 \ldots 3.0 \mathrm{~mm}$ & ca. $0.1 \ldots 3.0 \mathrm{~mm}$ \\
Velocity & $120 \ldots .280 \mathrm{~m} / \mathrm{s}$ & $110 \ldots .275 \mathrm{~m} / \mathrm{s}$ & $150 \ldots 450 \mathrm{~m} / \mathrm{s}$ & $175 \ldots 400 \mathrm{~m} / \mathrm{s}$ \\
\hline
\end{tabular}

energy-efficiency. A new particle acceleration system is presented by Uhlmann et al. [9]. It is also investigated by means of HSC experiments presenting particle velocities as a function of system parameters independent of the particle sizes. The most recent study dealing with energy-efficiency by Masa and Kuba [10] presents a specific energy consumption parameter to assess the efficiency of conventional and alternative dry-ice acceleration systems. In this work, particle velocities are estimated from system parameters. A simulation-based investigation of $\mathrm{CO}_{2}$ dry-ice blasting nozzles is presented by Dong et al. [11], where dry-ice acceleration behavior through a convergent-divergent nozzle is discussed as a function of system and particle parameters to find an optimized nozzle geometry. The particle sizes are kept constant, and only the particle mass flux and the particle shape factor are parameterized.

This work aims to present comprehensive flow information for $\mathrm{CO}_{2}$ dry-ice applications. In particular the dependency of particle size distributions from different nozzles as well as particle velocities in relation to their sizes are stressed. The comparability of $\mathrm{CO}_{2}$ dry-ice blasting flows to dilute, single POM particle laden flows is discussed. A comparison study of particle flow at injection and within the commercial aircraft engine is presented.

\section{EXPERIMENTAL SETUP}

\subsection{Free jet from nozzles}

The experimental setup for the single nozzle investigations varies only slightly from what is described detailed by the authors in Ref. [12]. The schematic from [12] is shown in a modified version in Figure 1. It consists of the compressor (1) and the dry ice blasting machine (2). Here, the particles being investigated (3) are introduced into the compressed air flow via a rotating perforated disc system. There is a $5 \mathrm{~m}$ long flexible connecting tube (4) linking the blasting machine (2) with the test nozzle (5), where the particles are accelerated.

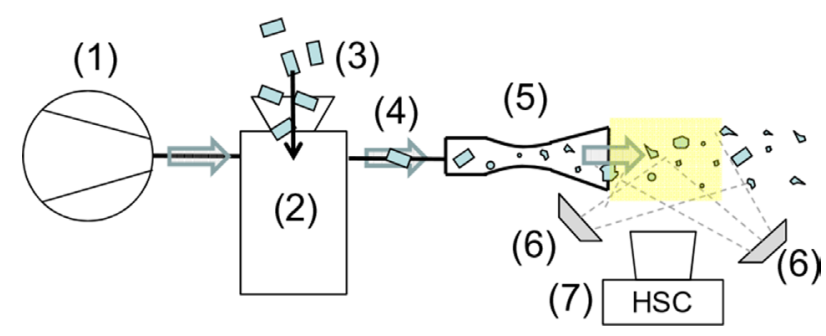

Figure 1: Schematic diagram of experimental nozzle setup. 
The pressure losses in section (4) are neglected. All given pressure values in this work are referred to as system pressure, which is preselected at (2). The HSC (7) (PCO dimax s4, monochrome) is positioned parallel to the particle laden free jet emerging from the nozzle (5)

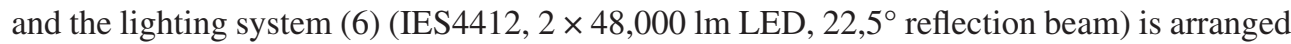
around it. The background behind the free jet is painted black to achieve a strong contrast to the particles. The nozzle assembly is positioned $40 \mathrm{~cm}$ above ground. The investigated area of the free jet begins directly after the nozzle outlet and comprises $50 \times 35 \mathrm{~mm}$, which is emphasized schematically in Figure 1.

The two nozzles used to generate the results presented here are a standard convergent divergent blasting nozzle, providing a supersonic outlet air flow while maintaining a system pressure of 8 bar (nozzle \#1) and a convergent nozzle, providing a sonic outlet air flow while operating it at a system pressure of 2 bar (nozzle \#2). Both nozzles have a rectangular (flat) shaped outlet area while their inlets (link between (4) and (5) in Figure 1) are circular. The outlet flow pattern is investigated in 2D. The depth direction of the velocity vectors is assumed to be negligible. The HSC is operated with a spatial discretization of $16 \mathrm{px} / \mathrm{mm}$ and a temporal discretization of 12,000 fps. The shutter time of one single frame is set to $1.28 \mu \mathrm{s}$. The settings permit the sizing of particles down to equivalent diameters of $125 \mu \mathrm{m}$ and to track particles at maximum velocities of $550 \mathrm{~m} / \mathrm{s}$.

\subsection{Aircraft engine flow}

To investigate particle flows within an aircraft engine, particles are shot into a commercial aircraft engine (GE CF6-50), which is being cranked via its starter on a test stand, without fueling and at speeds slightly below idle-speed. This procedure is shown schematically in Figure 2. Here, the particles are injected via the nozzle (5) into the engine's (ENG) low pressure compressor (LPC) (9). The particles pass through the LPC (9) into the high pressure compressor (HPC) (10). The results presented here are recorded directly at the inlet of the HPC (10).

To obtain the recordings, 3 inlet guide vanes are removed from the HPC to allow access for the HSC specified above (7) and the lighting system (6). The inlet guide vane mounting holes (diameter $35 \mathrm{~mm}$ ) are equipped with silica glass plates as to be optically accessible during dry cranking. The two lamps of the lighting system (6) are placed above and below the HSC. Removal of the guide vanes does not affect incoming particle flow.

To enhance the clarity of the recordings and minimize possible reflections, the background area of the HSC field of view is painted black. The incoming flow pattern is investigated in 2D.

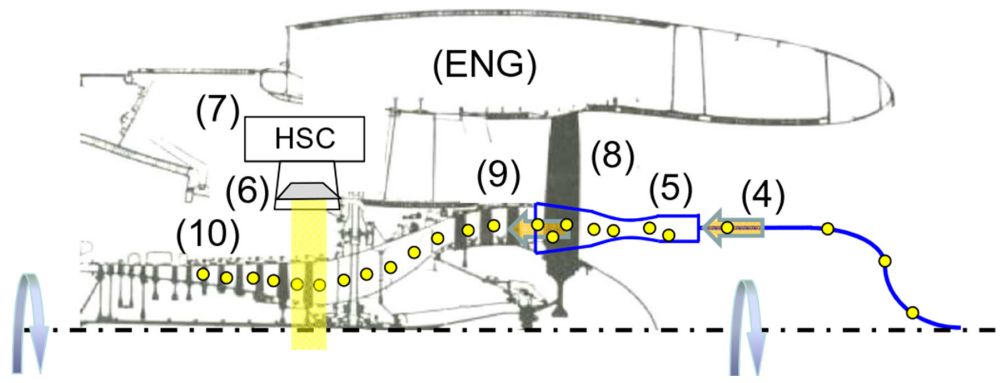

Figure 2: Schematic diagram of experimental engine setup. 
The HSC is set to a spatial discretization of $20 \mathrm{px} / \mathrm{mm}$ and a temporal discretization of $20.000 \mathrm{fps}$. The shutter time of one single frame is set to $5.12 \mu \mathrm{s}$. The acquisition system (6) and (7) is positioned parallel to the viewing windows and it is mounted on a separate rack. Initial investigations showed that vibration during operation had a negligible effect on the recording of particle velocities. Key dimensions related to the flow are presented in dimensionless form here.

\section{DATA PROCESSING PROCEDURE}

The HSC data acquired with the setups presented in section 2 is processed as follows to derive the desired physical outcomes. All postprocessing is realized by means of Matlab2014b procedures tested and validated by the authors.

After classifying image noise by means of spectral analysis, the resulting intensity matrices $\mathbf{I}$ are filtered utilizing an adjustable filter technique $F$ to obtain an improved intensity matrix $\mathbf{I}^{*}$ of the frame:

$$
\mathbf{I}^{*}(t)=F(\mathbf{I}(t)) .
$$

The resulting matrix $\mathbf{I}^{*}$ is used for a threshold valuing procedure. Background and particle information is distinguished by means of a clustering method presented by Otsu [13], providing the appropriate threshold value trv. The outcome of this procedure, eqn (2), is a second modified matrix $\mathbf{I}^{* *}$ of the frame. It contains only particle intensity values. All background values are set to 0 .

For sizing of the contained particles, the intensity matrix $\mathbf{I}^{* *}$ is treated as a binary matrix by regarding all intensity values higher than 0 as 1 . The result is subscripted $S$ and referred to as $\mathbf{I}_{S}^{* *}$ in what follows.

$$
I^{* *}(x, y)=\left\{\begin{array}{l}
0 \ldots \text { if } I^{*}(x, y)<t r v \\
I^{*}(x, y) \ldots \text { if } I^{*}(x, y) \geq \operatorname{trv}
\end{array}\right.
$$

Utilization of the modified matrix $\mathbf{I}^{* *}$ for a certain frame $(t)$ in an integral over the bounding box area $A_{b b}$ of each contained particle $i$ leads to the formulation of an energy vector $\varepsilon_{P, i}$ according to eqn (3). It contains the summarized intensity values of each particle of the frame $(t)$.

$$
\varepsilon_{P, i}^{\{t\}}=\iint_{A_{b b, i}} \mathbf{I}(t)^{* *} d x d y
$$

The same procedure is used to size the detected particles according eqn (4). It only utilizes the binary matrix $\mathbf{I}_{S}^{* *}$ instead of $\mathbf{I}^{* *}$. This leads to another vector $\alpha_{P, i}$. It contains the particle sizes (pixel count) of the particles $i$ contained in the investigated frame $(t)$.

$$
\alpha_{P, i}^{\{t\}}=\iint_{A_{b b, i}} \mathbf{I}(t)_{S}^{* *} d x d y
$$

This value is used to obtain the equivalent diameter $d_{P, i}$ of the corresponding particle $\mathrm{i}$ assuming its area $\alpha_{P, i}$ being the projected area of an ideal sphere:

$$
d_{P, i}^{\{t\}}=\left(\frac{4}{\pi} \cdot \alpha_{P, i}^{\{t\}}\right)^{\frac{1}{2}}
$$


Conversion of the results from eqn (5) with the corresponding spatial discretization from the experiment leads to a physical value:

$$
e_{P, i}^{\{t\}}=\varepsilon_{P, i}^{\{t\}} \cdot \alpha_{P, i}^{\{t\}}
$$

To obtain the velocity vector, a centroid matching approach between the associated particles of two consecutive frames is chosen (see e.g [14-16]). The ambiguity problem of particle association in dense laden flows is solved by utilizing the idea presented by Hering et al. [17]. The particle energy $\varepsilon_{P, i}$ from eqn (3) is modified by its size $\alpha_{P, i}$, eqn (4), resulting in a specific energy variable calculated according eqn (6).

The values $\mathrm{e}_{\mathrm{P}}$ from two consecutive time steps $\{t\}$ and $\{t+1\}$ are compared in a residual formulation which accounts for the values of a certain particle $i$ from the first frame $\{t\}$ and the values from all particles $(1: n)$ found in the second frame $\{t+1\}$ :

$$
C_{i}^{\{(t):(t+1)\}}=\min \left[\frac{\left|e_{P, i}^{\{t\}}-e_{P,(1: n)}^{\{t+1\}}\right|}{\left|e_{P, i}^{\{t\}}+e_{P,(1: n)}^{\{t+1\}}\right|}\right] .
$$

Its purpose is to find the minimum. This leads to an ambiguity matrix $\mathbf{C}$ containing all possible particle associations and their correlation probability ( $0=$ ideal, $1=$ no correlation). Considering slightly changing flow and ambient conditions from frame $\{t\}$ to frame $\{t+1\}$ by means of an acceptance limit (i.e. $C_{i, \max }=0.1$ ) and the knowledge of the general flow behavior from a priori estimations, the most probable particle pairs are associated. With the centroid matching approach, the 2D velocity vectors can be estimated for all particles $i$ :

$$
\mathbf{v}_{P, i}=\frac{\Delta \mathrm{x}_{i}}{\Delta t}
$$

\section{RESULTS}

All methods presented are systematically verified and validated. This comprises various tests with artificial matrices and the final validation of the sizing and tracking procedure by means of single POM particle flows. It reveals maximum deviations in the estimated particle sizes of $\pm 5 \%$ and maximum deviations in the particle velocities of $\pm 1 \%$. The known particle sizes from the POM particles are utilized as reference values for the sizing procedure. The tracking algorithm is validated against the outcomes from calculations by means of a Matlab IDL implementation according to Furst [18] and manual matches.

\subsection{Free jet from nozzles}

Figure 3 shows the mean relative intensity values (thick lines) bounded by the corresponding standard deviations (dash-dotted lines) encountered in several consecutive frames $\mathbf{I}(\mathbf{t})$ for the two nozzles investigated. The plots reveal a general impression of the flow characteristics. Peaks in intensity indicate large particles contained in the flow. Greater fluctuation in the plots indicates a more discontinuously laden flow. Comparison of the intensities from the supersonic nozzle \#1 (Fig. 3, left) to those from the sonic nozzle \#2 (Fig. 3, right) reveals the jet from nozzle \#1 being more discontinuously laden, containing more large $\mathrm{CO}_{2}$ dry-ice particles (more intensity peaks). The jet from nozzle \#2 is more continuously laden with fewer large particles (e.g. compare the two isolated large peaks in Figure 3, right, with the more generally distributed peaks in the left-hand figure). 

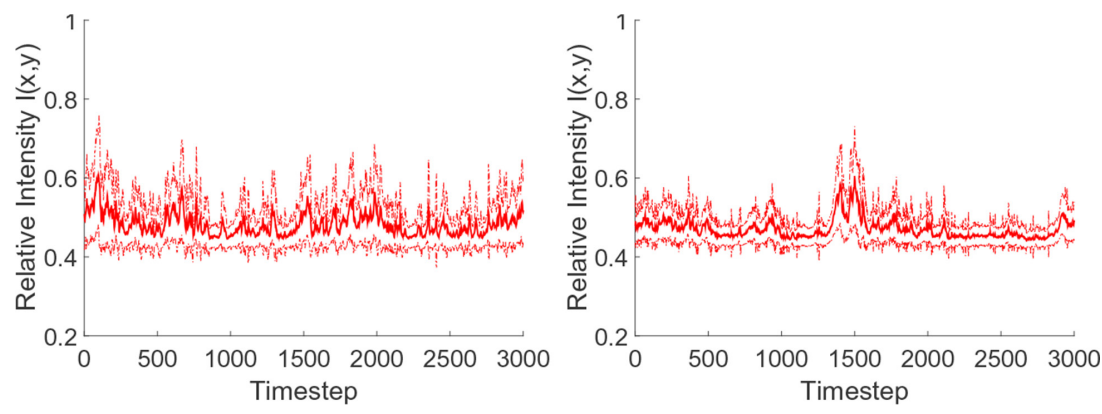

Figure 3: Intensity analysis of dry-ice laden jets from supersonic nozzle \#1 @ 8 bar (left) and sonic nozzle \#2 @ 2 bar (right).
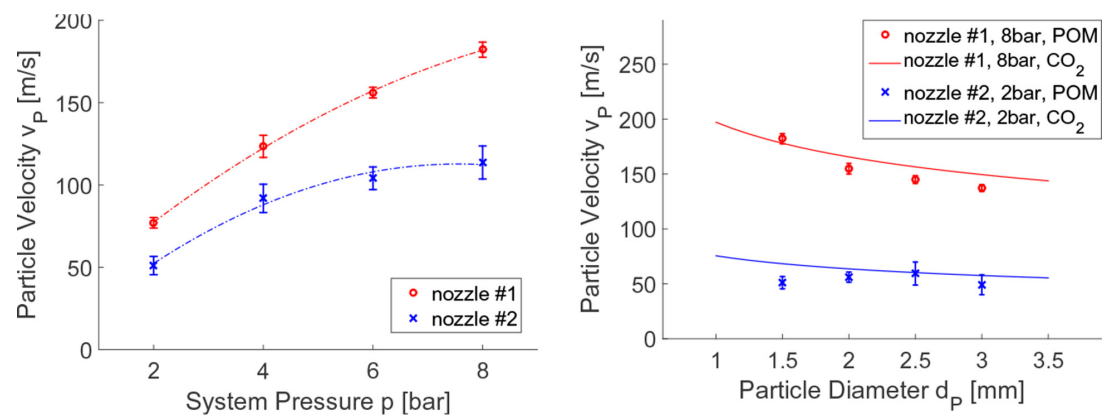

Figure 4: Single POM particle velocities (left) and comparison between large dry-ice particle and single POM particle velocities (right).

Following the above experiments, the particle flow behaviors from the supersonic (\#1) and sonic (\#2) nozzles are investigated by introducing single POM particles into the jet. Ideal spherical POM particles with diameters from 1.5 to $3.0 \mathrm{~mm}$ are injected into the flow and blasted using different system configurations. At least 40 POM particles are recorded and tracked downstream of the nozzle outlets. The main outcome of this study is shown in Figure 4, left. It contains the representative information of $1.5 \mathrm{~mm}$ POM particle velocities as a function of system pressure. The POM particles are accelerated by nozzle \#1 to velocities of $75 \mathrm{~m} / \mathrm{s}$ at a system pressure of 2 bar up to ca. $200 \mathrm{~m} / \mathrm{s}$ at a system pressure of 8 bar. Nozzle \#2 delivers single POM particles at velocities of $50 \mathrm{~m} / \mathrm{s}$ at 2 bar system pressure up to ca. $100 \mathrm{~m} / \mathrm{s}$ at 8 bar. The outcomes of this experiment are comparable to the results for other systems reported by Spur et al. [4]. A detailed validation study of POM particle acceleration in the inner nozzle is described by Rudek et al. in Ref. [12].

Detailed investigations into the $\mathrm{CO}_{2}$ dry-ice laden flows from both nozzles revealed the necessity to distinguish between large $\left(d_{P} \geq 1 \mathrm{~mm}\right)$ and small $\left(d_{P}<1 \mathrm{~mm}\right)$ particles. From these investigations, the velocities of large particles can be correlated as a function of their size for constant system pressure whereas this is not possible to a satisfactory degree for the small particles. In Figure 4, right, the correlated trends of large $\mathrm{CO}_{2}$ dry-ice particle velocities (full lines) are compared to the corresponding velocity trends from the POM particle investigations described above (circular markers = nozzle \#1, cross markers = nozzle \#2). The large 

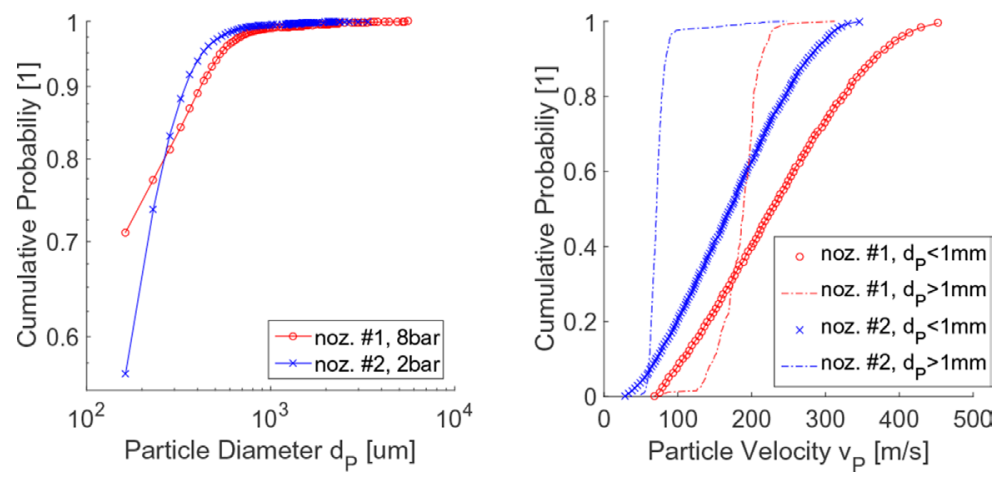

Figure 5: Particle size distributions (left) and particle velocity distributions (right) in dry-ice flows from blasting nozzles \#1 and \#2.

$\mathrm{CO}_{2}$ dry-ice particles behave in a comparable manner to the single POM particles. As for the large $\mathrm{CO}_{2}$ dry-ice particles transportation there seems to be no significant difference between a single particle POM flow and a denser laden $\mathrm{CO}_{2}$ dry-ice particle flow. Possible thermal effects due to heat-transfer from the air to the particles (i.e. cooling of the air and consequent changes in its flow properties) appear to be negligible for transportation of large particles.

As discussed in Figure 3, the supersonic nozzle \#1 delivers more large $\mathrm{CO}_{2}$ dry-ice particles compared to the sonic nozzle \#2. This can be seen from the cumulated particle size distributions in Figure 5, left. To determine these trends, a number of samples taken at random time points from the HSC recordings are used. Each trend shown in Figure 5, left, contains information from at least 40,000 single $\mathrm{CO}_{2}$ dry-ice particles. The cumulative trend for nozzle \#1 (Fig. 5, left, circular markers) reveals a wider spread in particle size than for nozzle \#2 with a larger proportion of smaller particles while also containing larger particles than from nozzle \#2. The comparison of the estimated diameter values reveal a mean size of $d_{P}=225 \mu \mathrm{m}$ for both nozzles while a higher variance is encountered for nozzle \#1.

Figure 5, right, contains the outcomes from the dry-ice particle tracking investigations. Here, 10 instants of time are selected randomly and 100 consecutive recordings starting at each of the instants are investigated. The trends shown in Figure 5, right, contain at least 5,000 single particle tracks. The full lines are indicated with circle-markers for nozzle \#1 and cross-markers for nozzle \#2. They show the cumulative particle velocity distributions considering small particle sizes. The dash-dotted lines show the cumulative particle velocity distributions for large particles only. The latter contain less than 5,000 particle tracks. Examination of the trend for large particles from nozzle \#1 reveals velocities from $150 \mathrm{~m} / \mathrm{s}$ to $200 \mathrm{~m} / \mathrm{s}$ while the according trend for nozzle $\# 2$ shows velocities between $50 \mathrm{~m} / \mathrm{s}$ and $75 \mathrm{~m} / \mathrm{s}$. This is also visible from Figure 4, right.

Regarding small particles clearly widens the distributions. Particle velocities for nozzle \#1 are found to be between $80 \mathrm{~m} / \mathrm{s}$ and $480 \mathrm{~m} / \mathrm{s}$ at an air velocity of ca. $580 \mathrm{~m} / \mathrm{s}$. These for nozzle \#2 are found to be between $40 \mathrm{~m} / \mathrm{s}$ and $320 \mathrm{~m} / \mathrm{s}$ at an air velocity of ca. $350 \mathrm{~m} / \mathrm{s}$. The large scattering can be explained by particle-particle and particle-wall interactions as well as 2-way-coupling phenomena influencing the continuous phase. Large particles can affect the particle paths of small particles, decelerating them mainly in the narrow parts of the nozzle. Also particle-wall collisions of small particles can decelerate them and small particles can be produced by disintegration of larger particles inside the nozzle. It should be noted that the 
study presented here does not distinguish between the core of the jet and its edges. Small particles traveling at the edges of the jets are affected by the strong shear layer and are therefore decelerated faster than similar particles being located in the jet's core or larger particles with a higher inertia. Further elaboration is necessary for proof of the above phenomena.

\subsection{Aircraft engine flow}

The methodology described above is utilized to investigate a $\mathrm{CO}_{2}$ dry-ice particle laden flow through a commercial aircraft engine (see Fig. 2). The main goal is to reveal the influence of the dry cranked compressor section, in this case the influence of the LPC, upon the particle laden flow characteristics. Figure 6, left, contains the cumulative particle size distributions from ca. 10,000 $\mathrm{CO}_{2}$ particles, while Figure 6, right, shows the trends of the cumulative particle velocity distributions from ca. 2,000 of these particles. The diamond-marked lines indicate the quantities at the blasting system outlet (nozzle FAN) and the star-marked trends show the outcomes from the measurements inside the engine at the first stage (IGVs) of the HPC (engine HPC).

Engine rotation clearly affects the particle characteristics. The particle size distribution at the HPC (engine HPC) is tighter than the particle size distribution at the blasting nozzle outlet (nozzle FAN) (Fig. 6, left). The mean particle diameter at the HPC inlet (engine HPC) is ca. 0.50 times the injected mean particle diameter (nozzle FAN). This indicates particle disintegration due to particle-wall collisions inside the LPC, which consists of a total 678 vanes and blades.

In contrast to the particle size distribution, the particle velocity distribution becomes wider due to engine cranking (Fig. 6, right). The velocity distribution is widened towards lower velocities. The mean particle velocity at the HPC inlet (engine HPC) is 0.56 times that at the nozzle outlet (nozzle FAN). The maximum velocity of single particles remains comparable. This decrease in velocity can be explained by particle disintegration.

\section{CONCLUSION AND OUTLOOK}

A HSC experiment for the characterization of inhomogenously and discontinuously laden $\mathrm{CO}_{2}$ dry-ice flows is utilized for the investigation of dry-ice blasting nozzles and aircraft engine cleaning flows. Large dry-ice particles showed similar transport behavior to single POM particles of the same size. The velocity of cleaning flow particles is presented in cumulative probability diagrams, which is assumed to be appropriate due to the large scattering
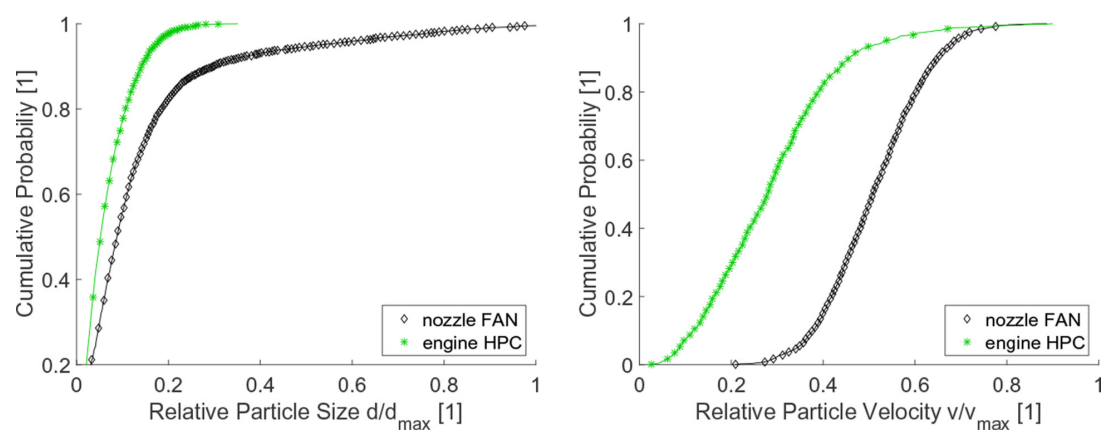

Figure 6: Particle size distributions (left) and particle velocity distributions (right) in dry-ice flow at the inlet and inside the engine. 
encountered. This scattering can be explained by complex interactions between particles, walls and the continuous phase. The influence of a turning LPC section upon the particle flow characteristics is clearly demonstrated. It is shown to result in smaller particle sizes and lower velocities. As future work, the understanding of particle size depending acceleration behavior in dense $\mathrm{CO}_{2}$ dry-ice flows is emphasized by the authors as well as a more detailed description of the dry-ice behavior inside aircraft engines.

\section{REFERENCES}

[1] Giljohann, S., Braeutigam, K., Kuhn, S., Annasiri, S. \& Russ, G., Investigations into the on-wing cleaning of commercial jet engines with $\mathrm{co}_{2}$ dry ice blasting. Deutscher Luftund Raumfahrkongress Berlin, 1, pp. 1-9, 2012.

[2] Foster, R.W., Carbon dioxide (dry-ice) blasting. Good Painting Practice: SSPC Painting Manual, 1, pp. 161-167, 2005.

[3] Stratford, S., Dry ice blasting for paint stripping and surface preparation. Metal Finishing, 98, pp. 493-499, 2000.

http://dx.doi.org/10.1016/S0026-0576(00)80450-X

[4] Spur, G., Uhlmann, E. \& Elbing, F., Dry-ice blasting for cleaning: process, optimization and application. Wear, 233-235, pp. 402-411, 1999.

http://dx.doi.org/10.1016/S0043-1648(99)00204-5

[5] Haberland, J., Reinigen und Entschichten mit Trockeneisstrahlen-Grundlegende Untersuchungen des CO2-Strahlwekzeuges und der Ver-fahrensweise (in german). Ph.D. thesis, University Bremen, 1999.

[6] Redeker, C., Erosion and Removal by Dry-Ice Blasting (in german), Ph.D. thesis, University Hannover, 2003.

[7] Redeker, C., Bach, F.W. \& Copitzky, T., Examination of the dry ice removal process for thermal sprayed coatings by particle image velocimetry. Thermal Spray: Advancing the Science \& Applying the Technology, 1, pp. 1279-1284, 2003.

[8] Krieg, M.C., Analyse der Effekte beim Trockeneisstrahlen (in german), Ph.D. thesis, Technical University Berlin, 2008.

[9] Uhlmann, E., Hollan, R. \& Mernissi, A.E., Dry ice blasting - energy efficiency and new fields of application. Engineering Against Fracture: Proceedings of the 1st Conference, 1, pp. 399-409, 2009.

[10] Masa, V. \& Kuba, P., Efficient use of compressed air for dry ice blasting. Journal of Cleaner Production, 111, pp. 76-84, 2016.

http://dx.doi.org/10.1016/j.jclepro.2015.07.053

[11] Dong, S.J., Song, B., Hansz, B., Liao, H.L. \& Coddet, C., Modelling of dry ice blasting and its application in thermal spray. Materials Research Innovations, 16, pp. 61-66, 2012. http://dx.doi.org/10.1179/1433075X11Y.0000000015

[12] Rudek, A., Russ, G. \& Duignan, B., An experimental and numerical validation study of particle laden supersonic flows. 9th International Conference on Multiphase Flow, 1, pp. 1-6, 2016.

[13] Otsu, N., A threshold selection method from gray-level histograms. IEEE Transactions on Systems, Man and Cybernetics, 9, pp. 62-66, 1979.

http://dx.doi.org/10.1109/TSMC.1979.4310076

[14] Adrian, R.J., Particle-imaging techniques for experimental fluid mechanics. Annual Review of Fluid Mechanics, 23, pp. 261-204, 1991. http://dx.doi.org/10.1146/annurev.fl.23.010191.001401 
[15] Brady, M.R., Rabenb, S.G. \& Vlachos, P.P., Methods for digital particle image sizing (dpis): Comparisons and improvements. Flow Measurement and Instrumentation, 20, pp. 207-219, 2009.

http://dx.doi.org/10.1016/j.flowmeasinst.2009.08.001

[16] Cheezum, M.K., Walker, W.F. \& Guilford, W.H., Quantitative comparison of algorithms for tracking single fluorescent particles. Biophysical Journal, 81, pp. 2378-2388, 2001. http://dx.doi.org/10.1016/S0006-3495(01)75884-5

[17] Hering, F., Merle, M. \& Wierzimok, D., A robust technique for tracking particles over long image sequences. Proceeding of ISPRS Intercommission Workshop: 'From Pixels to Sequences', 30, pp. 1-5, 1995.

[18] Furst, E.M., Particle tracking (cheg 667-016). Technical report, University of Delaware, 2013. 